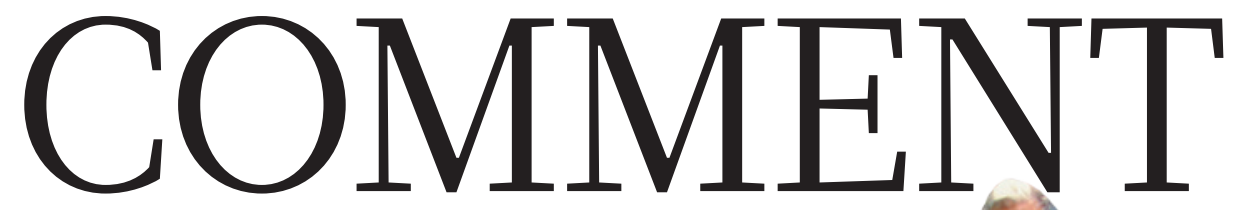

GOVERNANCE Don't fear the DIY biologists, learn from them $\mathbf{p . 1 6 7}$
ECONOMICS China’s fraught relationship with Latin America p.169
CONSERVATION Should half of Earth be set aside as wilderness? p.170
EPIDEMIOLOGY Standard

strain-naming urgently needed for Zika $\mathbf{p . 1 7 3}$

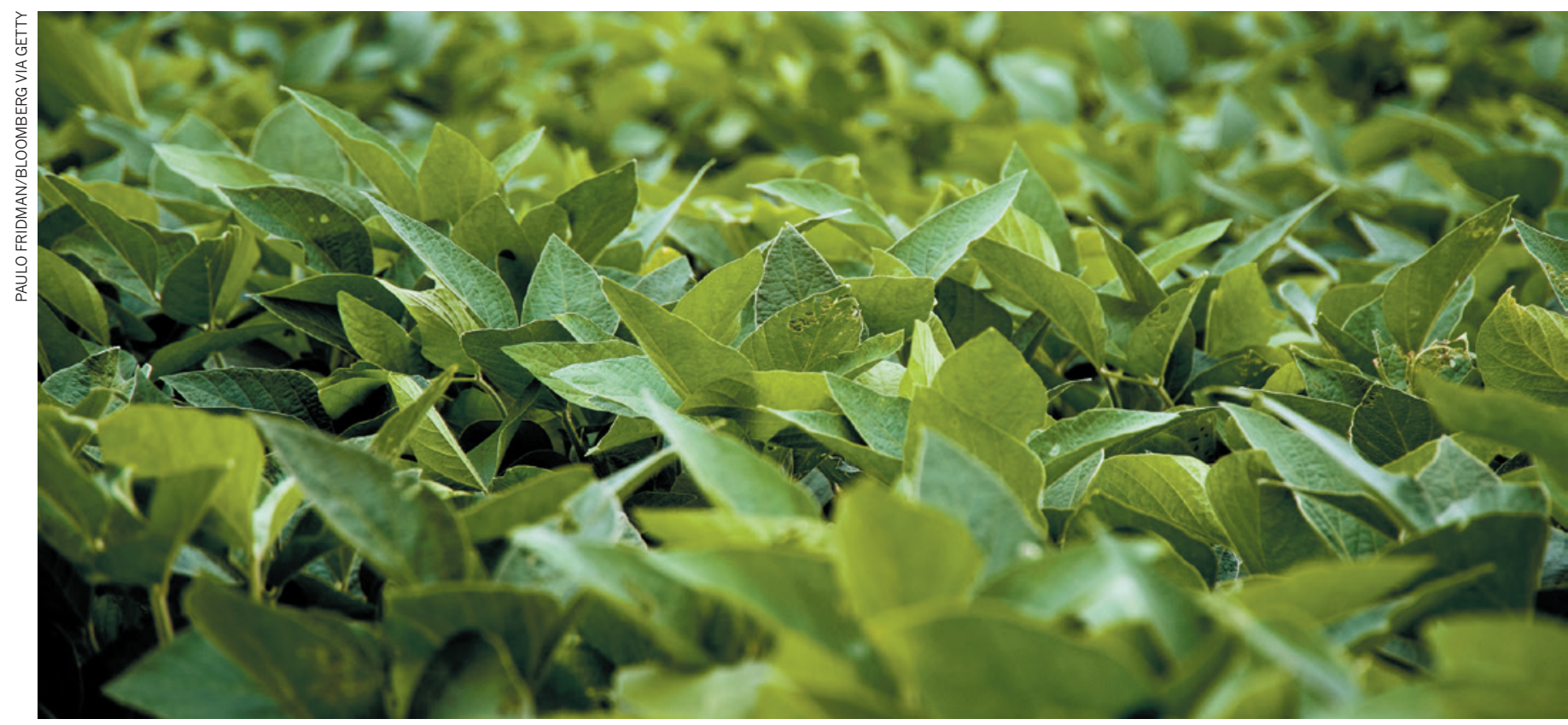

In the United States, engineered crops now make up more than $80 \%$ of the soya bean (pictured), maize and cotton acreage.

\title{
Reboot the debate on genetic engineering
}

Arguments about whether process or product should be the focus of regulation are stalling progress, says Jennifer Kuzma.

\section{$\mathrm{G}$} enetic engineering (GE) has become increasingly contentious in recent years. Thousands of citizens and stakeholders in the United States are currently striving to pass mandatory foodlabelling laws, ban certain GE products and create GE-free zones for growing food.

GE is the manipulation of an organism's genome through biotechnology or modern molecular techniques. It is also called genetic modification, although that term is understood by scientists to encompass older processes such as hybridization as well. With the wealth of possibilities now offered by newly developed gene-editing tools - particularly CRISPR-Cas9 - debates about the safe and appropriate uses of GE are becoming more heated. In fact, in the 20 years that I have been involved in discussions about it, oversight of GE has never seemed so much like a powder keg waiting to explode.

One issue that has dominated the debate is whether the focus of regulation should be the process by which GE organisms are made or the GE products themselves (the living organisms or products derived from them).

From 1999 to 2000, I directed a US National Academy of Sciences study (see go.nature.

\begin{tabular}{|l|l|}
\hline 19 & CRISPR EVERYWHERE \\
A Nature special issue \\
nature.com/crispr
\end{tabular}

com/lhyten) to investigate pest-resistant GE plants and their regulation. While working on that project, and in the years since, I have found that most people in favour of productbased regulation believe that there is no need to treat GE organisms differently from conventionally bred ones. Moreover, these people often claim that those who think that the process of engineering should be the focus of regulation - and thus, who want to see most or all GE products go through regulatory review before they enter the marketplace - are making arguments based on values or emotions, rather than science, to support their views.

But framing the debate around 'product versus process' is neither logical nor scientific. It is stalling productive 
$\checkmark$ dialogue on the development of appropriate oversight in the face of rapid advances in GE.

\section{IN A RUT}

The United States has had a system in place for overseeing GE products since the mid1980s: the Coordinated Framework for Regulation of Biotechnology (CFRB). The parties involved in the development of this framework - including representatives from the Office of Science and Technology Policy (OSTP) and various federal agencies - determined that it is the final product of GE that potentially poses a risk to human health and the environment, not the process by which the product is made ${ }^{1}$.

Product-led regulation was seen to be a science-based approach that would preclude the need for new biotechnology laws. It meant that GE organisms could be covered by existing laws for products intended to be used as pesticides, plant pests, toxic substances and so on; engineered organisms could be channelled to particular agencies - the Environmental Protection Agency (EPA), the Food and Drug Administration (FDA) and the US Department of Agriculture (USDA) - depending on what category they fell into.

So the intended use of a product has dictated which agency has the authority to regulate it under the CFRB. Yet, in practice, it is the process of GE that has been the 'regulatory trigger' used to capture products for pre-market review.

After the CFRB was published in 1986, each agency produced documents that detailed the specific protocol for the GEproduct categories under its purview. For example, the EPA described the steps that developers would need to take if they were marketing plants that have pesticidelike substances engineered into them, whereas the USDA laid out how developers should handle GE plants considered to be 'plant pests'.

These EPA and the USDA documents specified that organisms made by recombinant-DNA technologies or GE (but not their conventionally bred counterparts) must go through regulatory review before entering the marketplace.

The FDA took a different approach. It recommended through a guidance document - not a regulation - that developers of foods derived from 'new plant varieties' undergo a voluntary consultation process with the agency. This guidance did not exclude non-GE new plant varieties. In practice, however, developers of conventionally bred foods seem not to have undergone such consultations, whereas the FDA has been notified of more than 100 foods derived from GE plants (see go.nature.com/z78s1e).

For the EPA, the USDA and the FDA, the

\section{LOOSER SCRUTINY}

Because of changes to genetic-engineering (GE) processes, several GE crops have entered the US marketplace without review from the US

Department of Agriculture (USDA) in recent years.

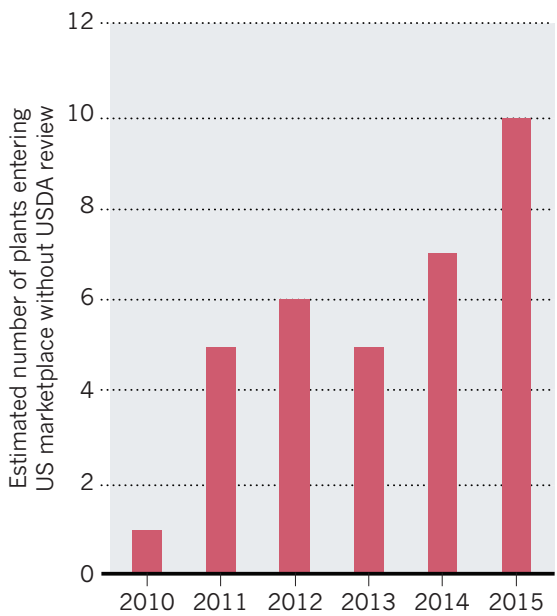

engineered product once again becomes the focus when the agencies actually assess the level of risk that it poses. But from a scientific standpoint, a product's traits harmful or otherwise - depend in part on the process by which it is made. (This is especially evident from human gene-therapy trials, where new methods for delivering genes have removed the need for potentially harmful viral vectors.) And in their review procedures, the agencies recognize that the process of engineering is important. The USDA, for example, requires a "detailed description of the molecular biology of the system ... used to produce the regulated article".

Thus, product and process issues are not distinct in regulation. Indeed, it does not make sense scientifically to try to value one approach more highly than the other.

The idea that regulating products is the only 'science-based' way has been popular with regulators and developers beyond the United States. For instance, plant scientist Ingo Potrykus, who led the development of the genetically engineered vitamin-Aenriched 'golden rice' variety at the Swiss Federal Institute of Technology (ETH) in Zurich, stated in 2010 that it would be a "crime against humanity" not to change from "regulating a technology on ideological terms" to "science-based regulation, guided by considerations of the risks and benefits of the trait" .

Yet many countries go further than the United States when it comes to processbased triggers for regulation, relying on national laws. In Brazil, a national biosafety law provides safety standards and oversight mechanisms for GE organisms; in Australia, the Gene Technology Act mandates a regulatory framework for the risk assessment and management of GE organisms.

\section{EMERGING TECHNOLOGIES}

The product-versus-process framing has के reared its confusing head again in recent discussions. Gene editing involves changing o DNA sequences at targeted locations, usually using site-directed nucleases (proteins that naturally cut DNA), such as CRISPR-Cas9, TALENS and zinc-finger nucleases. With these tools, genetic engineers can introduce one or a few nucleotide changes to a gene, make insertions or deletions in a gene sequence, or insert a different gene altogether, potentially from a different species. International discussions have focused on which types of gene-editing manipulation fall under regulatory definitions of GE organisms in different oversight regimes ${ }^{3}$.

Ironically, the same GE developers who once claimed that the process of GE does not matter for regulatory purposes are now arguing that changes to the engineering process justify looser regulatory scrutiny ${ }^{4}$. They contend that gene editing is a safer process than first-generation GE techniques owing to its precision and the smaller point mutations often made ${ }^{5}$.

And some US regulatory agencies are heeding these calls. Thanks to emerging methods of gene delivery and gene editing, genetic engineers no longer need to use DNA sequences from plant pests to introduce engineered genes into host plants. In part because of this change to the process by which the organisms are being made, the USDA has, for about five years, decided not to regulate about 20 engineered plants (see 'Looser scrutiny'). Several have entered the market without going through any formal regulatory review - either by the USDA or other agencies.

In Europe, crop developers are anxiously waiting for the European Commission to decide how changes to GE processes should
"It is impossible to be completely 'science based' in a regulatory system." affect regulatory policy. Specifically, the commission is expected soon to deliver a verdict on whether the definition of GE organisms covers gene-edited plants in which any foreign DNA used in the engineering process has been removed through selective breeding - and which are indistinguishable from wild plants that might have acquired the same mutation naturally (see Nature 528, 319-320; 2015).

GE developers and some regulators have been inconsistent in their product-versusprocess arguments for good reason. The dichotomy doesn't work, in practice or in theory. In fact, product-based arguments lead to one of two conclusions: if all products (GE or otherwise) are to be treated the same, then either all products - GE and conventionally bred - should be regulated, 
or neither should be. The first option is impractical and the second inadvisable given that some products could be harmful.

\section{A FRESH START}

It is time to reset the debate. Product-versusprocess arguments reflect world views about the desired level of regulation for GE organisms. These underlying viewpoints should be made explicit, and the idea that productbased regulation is the only science-based approach rejected.

In reality, it is impossible to be completely 'science based' in a regulatory system. Value judgements are embedded in all risk and safety assessments. For example, the doseresponse curve for a certain food additive might be known, but such data do not by themselves tell regulators where to set an acceptable safety limit. More often, the dose-response curve is not well established, or known at all. This uncertainty leads to various interpretations of the data.

Empirical evidence matters, but human interpretation brings meaning to that evidence, and multiple perspectives can strengthen understanding. Thus, an oversight system should focus on what concerns a diversity of stakeholders and citizens have, what evidence or risk-mitigation strategies can help to address those concerns, and what classes of GE products or processes should receive greater regulatory scrutiny. In practice, regulators and other stakeholders will need to consider a mix of product and process issues to capture product groups that are likely to be of greater concern.

Several models in the social-science literature describe how such democratic deliberation might be achieved ${ }^{6}$. And Norway's decision-making about GE organisms under its gene-technology act demonstrates how factors outside 'science-based' health or environmental harms can be incorporated into formal regulatory processes in practice. Since 2005, regulators in Norway making decisions about whether a GE organism will be released into the environment consider the results of safety reviews, and whether participants of a consultation process perceive that the organism provides a better option than alternatives and contributes to sustainable agricultural practices (see go.nature.com/5nxzcn).

There is a chance to start over, in the United States and elsewhere. In part because of advances in gene editing and a greater diversity of GE organisms being presented to regulators, the OSTP initiated a process in
July 2015 to clarify which regulatory authority is responsible for what under the $\mathrm{CFRB}^{7}$. And just last month, the USDA published four possible scenarios for a proposed new framework for the regulation of GE crops ${ }^{8}$.

Within these efforts and others, stakeholders could do away with polarizing product-versus-process and science-versusvalues framings, and help to establish a governance system that is both informed by the science and guided by the concerns and values of citizens.

Jennifer Kuzma is distinguished professor in the social sciences and co-director of the Genetic Engineering and Society Center at North Carolina State University, USA.

e-mail:jkuzma@ncsu.edu

1. OSTP. Fed. Reg. 51, 23302 (1986).

2. Potrykus, I. N. Biotechnol. 27, 466-472 (2010).

3. Wolt, J. D., Wang, K. \& Yang, B. Plant Biotechnol. J. 14, 510-518 (2015).

4. Huang, S., Weigel, D., Beachy, R. N. \& Li, J. Nature Genet. 48, 109-111 (2016).

5. Kokotovich, A. \& Kuzma, J. Bull. Sci. Technol. Soc. 34, 108-120 (2014).

6. Ramachandran, G. et al. J. Nanopart. Res. 13, 1345-1371 (2011).

7. Waltz, E. Nature Biotechnol. 33, 1221-1222 (2015).

8. USDA. Fed. Reg. 81, 6225-6229 (2016).

\section{Learn from DIY biologists}

\section{The citizen-science community has a responsible, proactive attitude that is well suited to gene-editing, argues Todd Kuiken.}

$\mathrm{O}$ ne of the top science stories of 2012 involved a furore about the wisdom of enhancing the transmissibility of the H5N1 avian influenza virus in ferrets. In that same year, fears mounted that do-it-yourself (DIY) biologists would cook up their own versions of the virus using information published in the academic press.

Now, journalists and others are again targeting the citizen-science community - a group of people with or without formal training who pursue research either as a hobby or to foster societal learning and open science - amid fears about the nascent gene-editing technology CRISPR-Cas9. In January, the San Jose Mercury News ran an article under a pearl-clutching headline: "Bay Area biologist's gene-editing kit lets do-it-yourselfers play God at the kitchen table." And although they are much less alarmist, scholars are advising policymakers to consider the potential uses of gene editing "outside the traditional laboratory setting" (R. A. Charo \& H. T. Greely Am. J. Bioeth. 15, 11-17; 2015).

The reality is that the techniques and expertise needed to create a deadly insect or virus are far beyond the capabilities of the typical DIY biologist or community lab. Moreover, pursuing such a creation would go against the culture of responsibility that DIY biologists have developed over the past five years. In fact, when it comes to thinking proactively about the safety issues thrown up by biotechnology, the global DIY-biology community is arguably ahead of the scientific establishment.

\section{EASY ACCESS}

The equipment and reagents that are needed to use CRISPR-Cas9 are already readily available to DIY biologists. Members of the teams that participated in the 2015 International Genetically Engineered Machine (iGEM) competition - including high-school students and users of community labs around

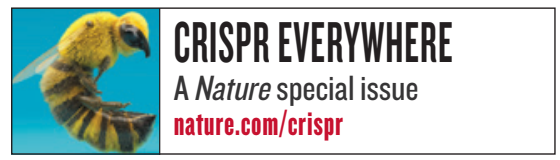

the world - received CRISPR-Cas9 plasmids in their starting kits. These kits contain more than 1,000 standard biological parts known as BioBricks, the DNA-based building blocks that participants need to engineer a biological system for entering into the competition. Other components of the CRISPR-Cas9 system are also available from the iGEM registry (http://parts.igem.org/CRISPR).

Yet few DIY biologists seem to be using the technology. Both Tom Burkett, founder of the Baltimore Under Ground Science Space in Maryland, and Ellen Jorgensen, executive director of Genspace - a community lab in Brooklyn, New York - say that their users are interested in CRISPR-Cas9, and Genspace will be offering a workshop on it in March. But none of the projects currently being pursued in these spaces require it. Users of the La Paillasse community lab in Paris are similarly focused on projects that do not need CRISPR-Cas9.

The materials might be available, but the knowledge and understanding needed to make edits that have the desired effects 